\title{
AC 2012-3239: USING MATLAB TO TEACH ELECTRIC ENERGY COURSES
}

\section{Dr. Max Rabiee P.E., University of Cincinnati}

Max Rabiee earned his Ph.D. in electrical engineering from the University of Kentucky (U.K.) in 1987. $\mathrm{He}$ has taught electrical engineering and electrical engineering technology courses full-time and part-time for more than 30 years, and he is currently professor in the School of Electronic and Computing Systems (SECS) in the College of Engineering and Applied Science (CEAS) at the University of Cincinnati (UC). Rabiee is a registered Professional Engineer (since 1988) and a Senior Member of the Institute of Electrical and Electronic Engineering (IEEE). He is also a member of the American Society of Engineering Education (ASEE), the Eta Kappa Nu Electrical Engineering Honor Society, and the Tau Beta Pi Engineering Honor Society. 


\section{Using MatLab to Teach Electric Energy Courses}

\section{Introduction:}

Electric machines are classified either as Direct Current (DC) or Alternating Current (AC). An Electric machine is either a motor or a generator. Electric motors are also classified according to their power rating, usage, and torque-speed characteristic curves. Electric generators are generally classified according to their Apparent Power called Kilo Volt Ampere (KVA) capacity.

Electric motors are rated as either Integral Horsepower or Fractional Horsepower. Integral Horsepower motors are rated at one horsepower or more, while Fractional Horsepower motors are rated at less than one horsepower. Electric motors according to their operational tasks are rated as Continuous or Intermittent Duty motors. Devices requiring continuous operation, such as electric fans, use continuous duty motors, while items such as electric compressors, that require a cyclical and short period of usage, utilize Intermittent Duty motors.

The author of this paper has taught electric machine classes in both semester and quarter systems in electrical engineering (EE) and electrical engineering technology (EET) programs. He has also worked in industry, where he was responsible for designing, specifying, testing, and analyzing electro-mechanical devices. In this paper, the author will describe topics that should be included in an electric rotating machine course and explain why using Matlab is an efficient method for students to solve lecture problems and analyze laboratory data.

Due to the time constraint in one quarter, seven (7) important AC and DC laboratory assignments pertaining to electric machines are selected for this course. Using MatLab enables the in-depth teaching of these topics during the ten-week quarter period. In the following sections of this paper, he will describe the subjects that he teaches in an electric rotating machine class, during one quarter.

\section{Power in Three Phase System and Transformers:}

During the first two (2) weeks, a quick overview of the three-phase sequence, and the impact of phase sequence is discussed. Three-phase power calculations are also studied in conjunction with learning how to determine line or phase voltages and currents, in y-connected and deltaconnected systems. The MatLab assignment sets pertaining to these topics are listed below.

Complex number systems; Polar to Rectangular conversion and vice versa, and polar and/or rectangular Addition/Subtraction/Multiplication/Division.

$>$ Line/Phase voltages, line/phase currents and single phase/total power in Delta-Delta, Delta-Wye, Wye-Delta and Wye-Wye systems.

During the third week, transformer principals and connections are reviewed. Calculating transformer equivalent circuits is also taught during this week. MatLab assignment sets pertaining to transformers are listed below. 
Calculate current, voltage and efficiency for constant input voltage with variable loads.

Calculate current, voltage and efficiency for constant output voltage with variable loads.

Using data from Open Circuit and Short Circuit tests to calculate primary resistance (R1), primary reactance (Xf1), core loss resistance $(\mathrm{Rm})$ which consists of hysteresis and eddy current losses, magnetizing reactance $(\mathrm{Xm})$, secondary resistance $(\mathrm{R} 2)$ and secondary reactance (X2f). Figure 1 shows the equivalent circuit of a transformer [1].

Three (3) laboratory experiments are assigned in order to complement the classroom teachings of the aforementioned topics . A brief description of these experiments is listed below. Students are required to use MatLab for determining the parameters for the "pre-lab" reports, and analyzing the data collected in the laboratory for their "post-lab" reports.

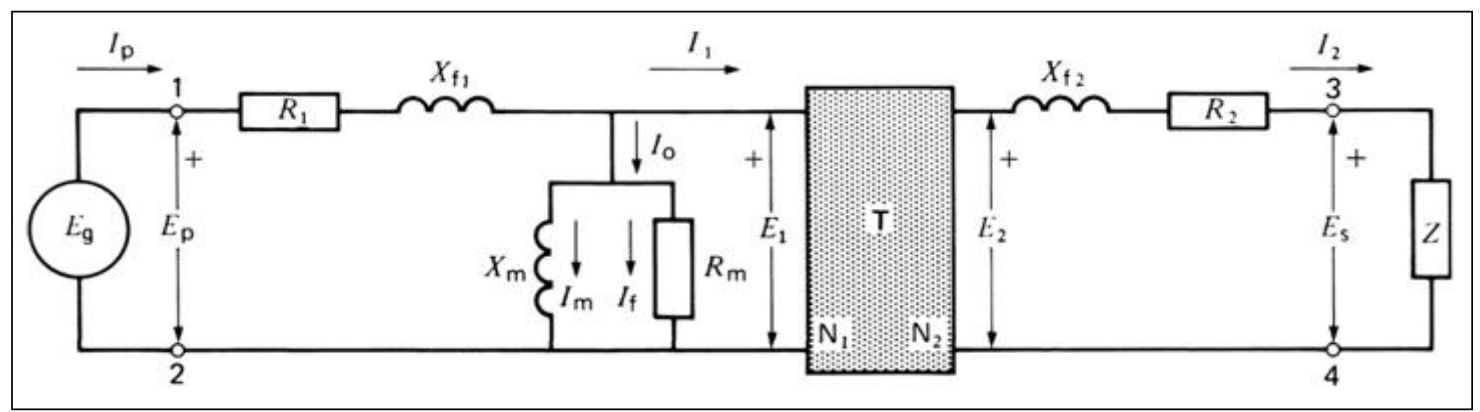

Figure1- Transformer Equivalent Circuit

In experiment \#1 entitled "Three-Phase Systems \& Phase Sequence", students make the connections for two (2) Wye-connected, unbalanced loads systems. Each connected system's operation is sensitive to the phase sequence of the three-phase voltage source. In experiment\#2 entitled "Power in Three-Phase Systems", students will use the "two analog wattmeter " and "three analog wattmeter" methods to measure power in Wye and Delta connected three phase loads. They will then compare the results with the data collected using one three-phase digital wattmeter. In experiment \#3 entitled "Transformer Characteristics and Efficiency", students will perform the "open circuit" and "short circuit" tests on a transformer to determine its equivalent circuit, and then they will perform load tests on the transformer to calculate its efficiency.

\section{Machine Classification and Characteristics:}

During the next three week period, direct current machines' operations and characteristics are the subjects which are reviewed. In the following section we describe these topics. DC machines are classified according to their armature and field wiring diagrams. There are four methods of connecting and exciting wound-field DC motors, which have both wound stator and wound rotor windings; (1) Separately Excited, (2) Series, (3) Shunt, and (4) Compound [3]. A separately excited DC motor can be controlled by either changing the line voltage or the field voltage. Figure 2 shows a separately excited motor's connection [3]. Varying the line voltage 
will result in having a variable speed for constant torque, while changing field current varies both speed and torque.



Figure 2- Separately-Excited DC Motor

In the Series Connected DC motor, field and armature coils are connected in series (See Figure 3). The field coil typically consists of a few turns of thick wire that have little resistance. Magnetic flux is proportional to field current If. Since field current If is equal to armature current Ia, then torque is proportional to armature current squared. If we increase the load, the speed will decrease causing an increase in series field and armature currents. Increasing armature current will generate more developed torque $\mathrm{T}$.

$$
\begin{aligned}
& \text { If }=\mathbf{I a}=(\text { Vapplied }- \text { Vcemf }) /(\mathbf{R f}+\mathbf{R a}) \\
& \text { Vcemf }=\operatorname{Ke}^{*} \boldsymbol{\varphi} * \mathbf{N} \\
& \mathbf{T}=\mathbf{K t} * \mathbf{I a} 2
\end{aligned}
$$

Maximum torque is generated when the motor is not moving. When the load decreases, the speed increases (See Figure 4.) The speed can increase dangerously to the point of destroying the motor if the DC series motor's load is reduced to zero.

$$
\mathbf{N}=(\text { Vapplied }- \text { If } *(\mathbf{R f}+\mathbf{R a})) / \text { If Ke }
$$

Speed regulation is the ability of a motor to maintain its rated speed as load on the rotor shaft is changed. Lower speed regulation is desirable since it implies that the motor can hold its set speed.

$\%$ Speed Regulation $=((\mathbf{N}$ no load $-\mathbf{N}$ full load $) / \mathrm{N}$ full load $) * 100$ 
A direct current (DC) series motors speed regulation is very poor (See Figure 4.) Due to the "run-away speed" danger, load must not be connected to the DC series motor via belt or chain. High starting torque characteristic is the great advantage of a DC series motor. Also, per pound power obtained from a DC series motor is greater than other DC motor configurations. DC series motors can run at high speeds of up to 10,000 RPM. DC series motors are used in Hoists, Cranes, and Locomotives. Sometimes a locomotive travels downhill such that the armature turns fast enough to generate larger Counter EMF voltage (VCEMF) than the applied voltage (Vapplied). In these instances, the DC series motor is acting like a generator. The counter torque associated with the generator will oppose the driving force (i.e., force due to the gravity); hence "regenerative braking" occurs.

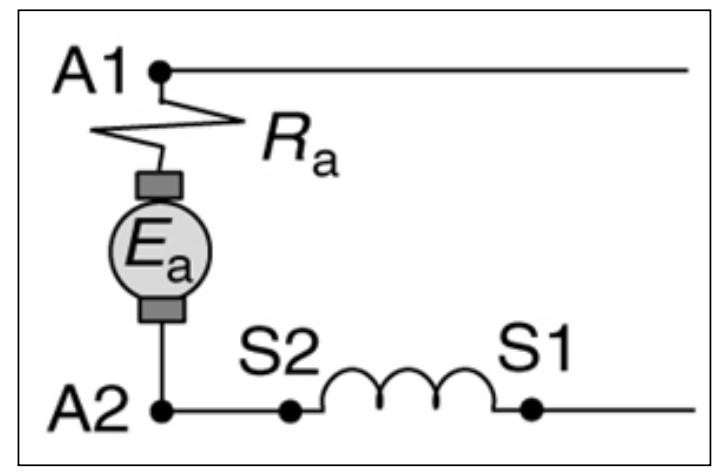

Figure 3- Series DC Motor

In Shunt DC motors, field and armature windings are connected in parallel (See Figure 5). The field coil consists of many turns of thin wire. Therefore, field resistance is greater in a Shunt DC motor. If applied voltage is held constant, then the field flux will be constant. Therefore, the only torque generated at no load is for overcoming friction and windage losses.

$$
\begin{aligned}
& \text { Vcemf }=\mathbf{K e}^{*} \mathbf{N} \boldsymbol{*} \boldsymbol{f} \\
& \mathbf{T}=\mathbf{K t} * \mathbf{I a} * \mathbf{I f}
\end{aligned}
$$

Counter EMF voltage, VCEMF will limit the amount of armature current flow. When the motor is loaded, motor speed $\mathrm{N}$ will decease and more armature current (Ia) will flow resulting in higher torque being generated.

$$
\begin{aligned}
& \mathbf{N}=\mathbf{V c e m f} /\left(\operatorname{Ke}^{*} \boldsymbol{\varphi f}\right) \\
& \mathbf{N}=(\text { Vapplied }-\mathbf{I a} * \mathbf{R a}) /\left(\mathrm{Ke}^{*} \boldsymbol{\phi f}\right)
\end{aligned}
$$

Magnetic flux $\varphi f$, is proportional to field current, If. If the applied voltage Vapplied and the field current (If) remain constant, then the speed will remain relatively constant. A Shunt DC motor can be designed to have as low as 1\% speed variation from no load to full load (See Figure 4). 


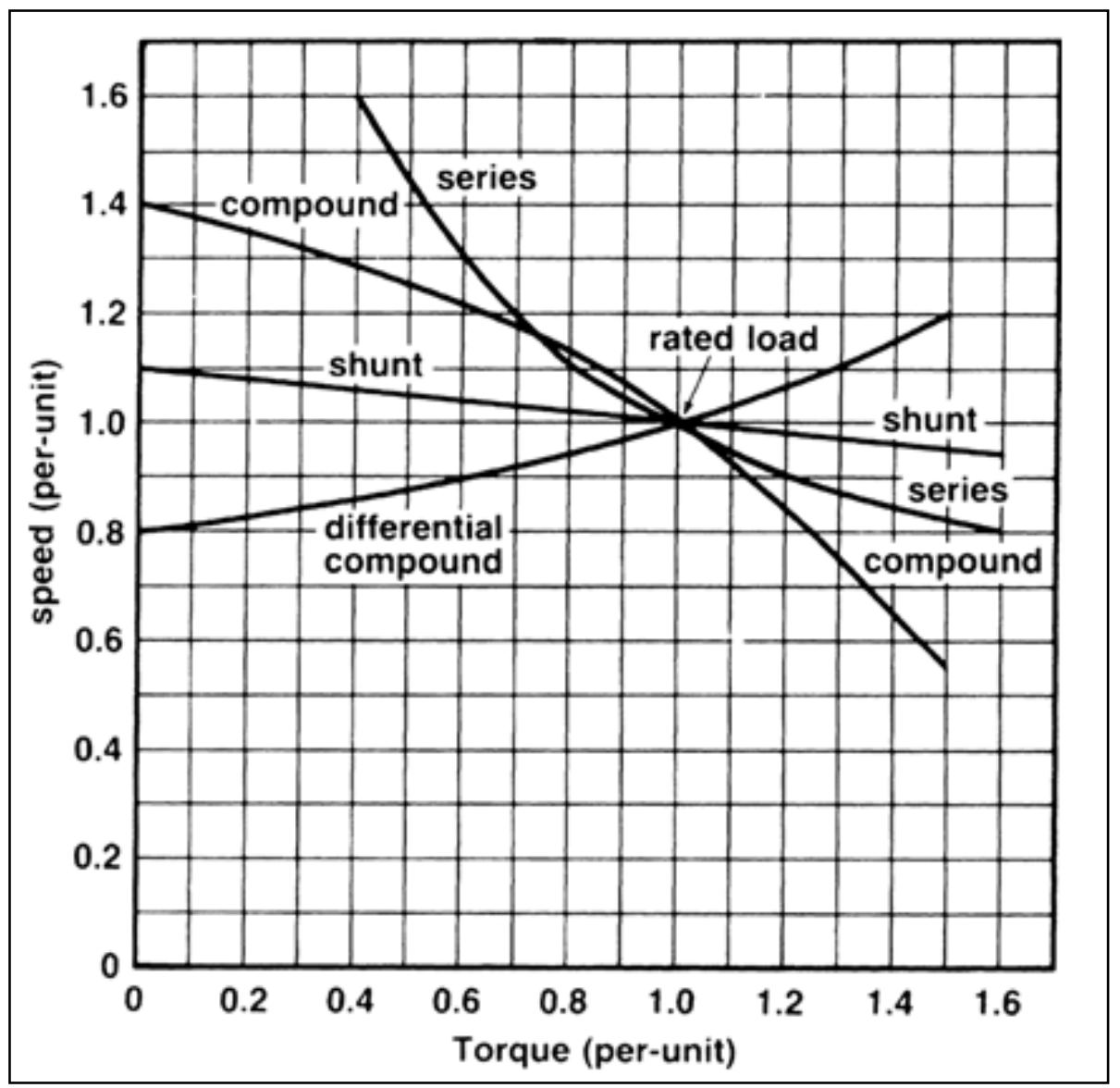

Figure 4- Typical DC Motors' Torque-Speed Characteristic Curves

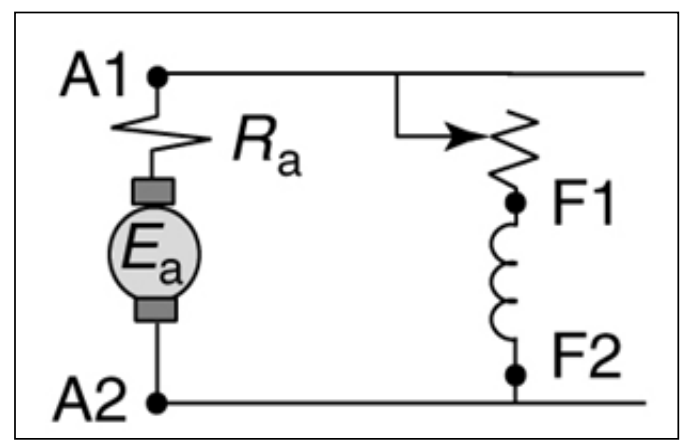

Figure 5- Shunt DC Motor

Armature flux can increase due to an increase in armature current. This is caused by loading the motor. Total flux strength $\varphi$ in the air gap will decrease $(\varphi=\varphi f-\varphi \mathrm{a})$. If the field current is reduced to a small value, motor speed will increase dangerously. Therefore, the field winding must not be disconnected during the Shunt DC motor operation. Shunt DC motors are used in applications where constant speed is required, such as elevators and conveyor belts. In some applications, we need the high starting torque characteristic of series DC motors and the constant 
speed characteristic of shunt DC motors. Compound DC motors have both series and shunt field windings (See Figure 6.). There are two types of compound DC motors; Cumulative Compound and Differential Compound. In the Cumulative compound DC motor, series and shunt field fluxes are both in the same direction and therefore add up (i.e., cumulative compound.) Under a full-load condition the series windings help to produce a stronger field and therefore more torque. However, under a no-load condition the shunt winding helps in creating a weaker field, hence the "danger of runaway speed" exists. Speed regulation of a cumulative compound motor is worse than that of a shunt motor (See Figure 4), but it will generate larger torque. In Differential compound motors, series and shunt fields are in opposite directions and therefore subtract from each other. For larger loads the series field strength is stronger than that of the shunt field, for smaller loads the series field strength is weaker than that of the shunt field. In both cases the fields subtract from each other, therefore a constant motor speed condition is possible. This motor has steady speed regulation, but small start up torque. However, under heavy loads the speed is unstable (See Figure 4). Usually, AC motors instead of differential compound DC motors are utilized.

Figure 7 displays the DC generator curve characteristics. The prime mover rotates the rotor shaft. Then, generated DC current is taken out of the stator windings. Note that typically, DC generators are connected in shunt form.

Two (2) laboratory experiments are assigned in order to complement the classroom instructions. A brief description of these experiments is listed below. Students are required to use MatLab for determining the pre and post laboratory parameters. In experiment \#4, DC machines on Hampden stations are connected in shunt motor configuration and data is collected to plot the Speed-Load Characteristic curves. In experiment \#5, DC machines on the Hampden stations are connected in compound generator configurations, and data is collected to plot the V-I characteristic curves.

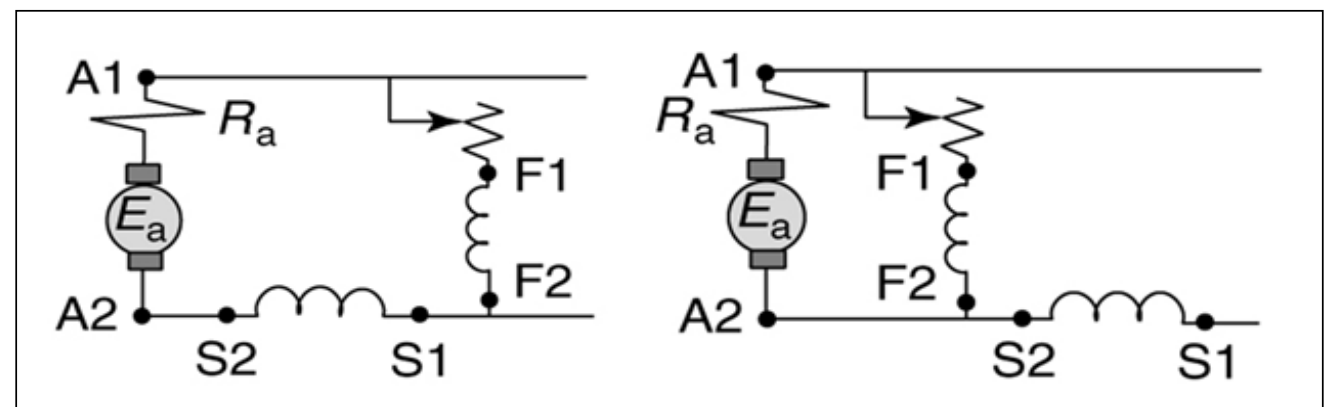

Figure 6- Long-shunt and Short-shunt Cumulative Compound DC Motor Field Connection 


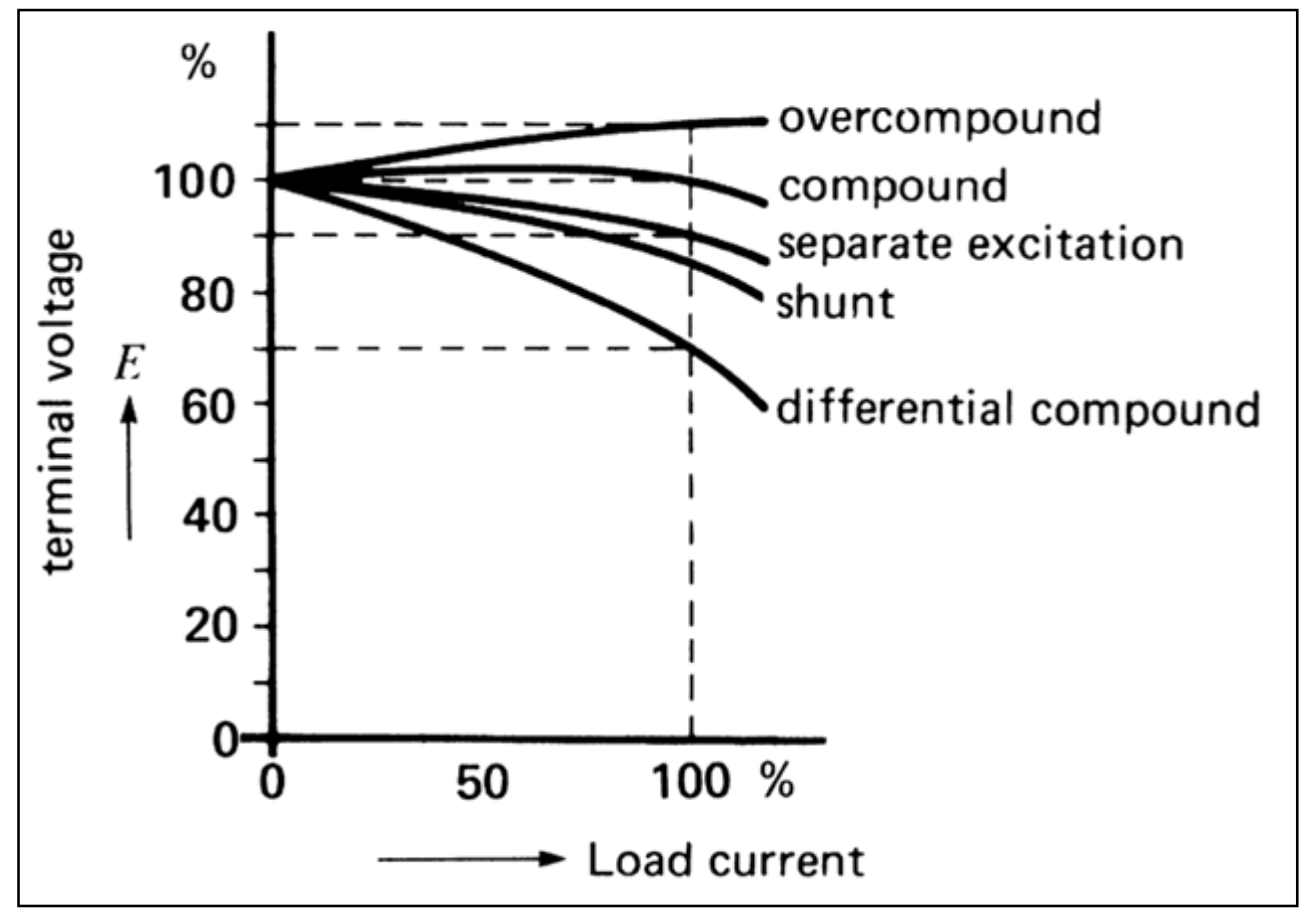

Figure 7- Typical DC Generator Load Characteristic Curves

\section{AC Machine Classification and Characteristics:}

During the last four weeks of the quarter, alternating current machines' operations and characteristics are the subject of study. In the following section we describe these topics. Alternating Current (AC) motors are more often used in industry where AC voltage is readily available. Single-phase AC motors are typically rated for $120 \mathrm{~V}$ or $240 \mathrm{~V}$, while three-phase AC motors are rated for $208 \mathrm{~V}, 240 \mathrm{~V}, 480 \mathrm{~V}, 600 \mathrm{~V}$, or more. Very large AC motors have power ratings from $200 \mathrm{HP}$ up to $100,000 \mathrm{HP}$. They typically start at $480 \mathrm{~V}$, and gradually the input voltage increases until they reach a continuous operating voltage level [3]. During the continuous operating interval, these large motors have applied voltages of $2300 \mathrm{~V}, 4000 \mathrm{~V}$, $6900 \mathrm{~V}$, or $13200 \mathrm{~V}$.

The principal of a rotating rotor in an AC motor is based on the fact that the stator magnetic field will rotate and the rotor magnetic field is attached and pulled along. If we assume that the stator magnet fields are free to move, then the south pole of the rotor is attracted to the north pole of the stator and repulsed by the south pole of the stator. Hence, the moving stator magnetic field will pull the rotor along. Generally, there are electromagnets on the stator. This means that there are coil windings housed in the slots of the laminated stator iron core. These coils are excited with AC current.

For a two-pole electric motor that is excited with a two-phase current, windings are placed 90 degrees apart. Then when the current goes thru one sinusoidal cycle the flux $\varphi$ will rotate a full revolution. Therefore, the speed of the rotor is equal to the frequency of the supply voltage. On the other hand, if the stator has four winding coils placed 45 degrees apart, it is called a four-pole 
stator. When the rotor travels from a North Pole to a South Pole and back to another North Pole, one electrical cycle has been completed. In a four-pole machine, the rotor speed is one half the electromagnetic field speed.

In a two-pole $\mathrm{AC}$ motor that is excited with a three-phase $\mathrm{AC}$ current, three winding coils are placed around the stator. The starting points of the winding coils are 120 degrees apart. Hence, for a $60 \mathrm{~Hz} \mathrm{AC}$ current, the rotor rotates at $3600 \mathrm{RPM}$. In a three-phase, four-pole AC motor that is excited with three-phase AC current, six winding coils are placed around the stator. The starting points of the winding coils are place 60 degrees apart. Then, for a $60 \mathrm{~Hz} \mathrm{AC}$ current supply, the rotor rotates at 1800 RPM. Therefore, the synchronous speed of an AC motor is calculated using the following equation.

$$
\mathrm{N}_{\mathrm{s}}=120 \mathrm{f} / \mathrm{P}
$$

There are two main types of AC motors; Induction Motors and Synchronous Motors. The Induction motor's stator is energized with AC current. The rotor is not connected to a supply. The alternating electromagnetic field generated by the stator will induce voltage in the rotor windings that will cause current flow. This rotor current in turn will generate a rotating rotor magnetic field that will attempt to align itself with the rotating stator field. This will cause the rotor to rotate. There are two types of induction motors; Squirrel Cage Induction Motors and Wound Rotor Induction Motors.

Most induction motors have Squirrel Cage Rotors (SCIM). The rotor bars are embedded in the rotor slots and are connected together by two end rings. The rotor current will take the path of "least resistance", therefore it is not necessary to insulate the rotor bars from the core. When the rotor speed increases, the rate at which the stator field cuts the rotor bar will decrease and hence rotor current and rotor frequency will decrease. Less rotor-current results in a lesser rotor electromagnetic field. It is therefore impossible, for the rotor to rotate at the speed of the rotating stator field. Slip is defined as the difference between the rotor speed and stator field speed, and is called synchronous speed.

$$
\begin{aligned}
& S=\left(N_{S}-N_{R}\right) / N_{S} \\
& f_{r}=S * f_{s}=S * f \\
& T=K * \varphi^{*} I_{R} * \operatorname{Cos}\left(\theta_{R}\right) \\
& \text { P.F. }=\operatorname{Cos}\left(\theta_{R}\right)=\tan ^{-1}\left(\left(f^{*} S^{*} L_{r}\right) / R_{r}\right)
\end{aligned}
$$

Figure 8 displays the torque-speed characteristic curve of a typical Squirrel Cage Induction Motor (SCIM). Notice that the induced rotor current $\mathrm{I}_{\mathbf{R}}$, and the stator flux $\varphi$ are proportional to the stator voltage. Therefore motor torque $\mathrm{T}$, is proportional to the stator voltage squared. If we 
differentiate $I_{R} * \operatorname{Cos}\left(\theta_{R}\right)$ in equation (13), and set it equal to zero, then for $I_{R} * \operatorname{Cos}\left(\theta_{R}\right)$ to be maximum, the rotor phase angle $\theta_{\mathrm{R}}$ must be 45 degrees. Therefore, for a constant flux strength $\varphi$, pull out or maximum torque is found when $\theta_{\mathrm{R}}$ is 45 degrees. When a load larger than the pull out torque is placed on the motor shaft, the induction motor will stall. The full-load of an induction motor is the load it can carry at the rated speed. At rated speed and rated torque, the induction motor has a slip value of 3.5 percent ( $\mathrm{S}$ rated $=3.5 \%$ ).

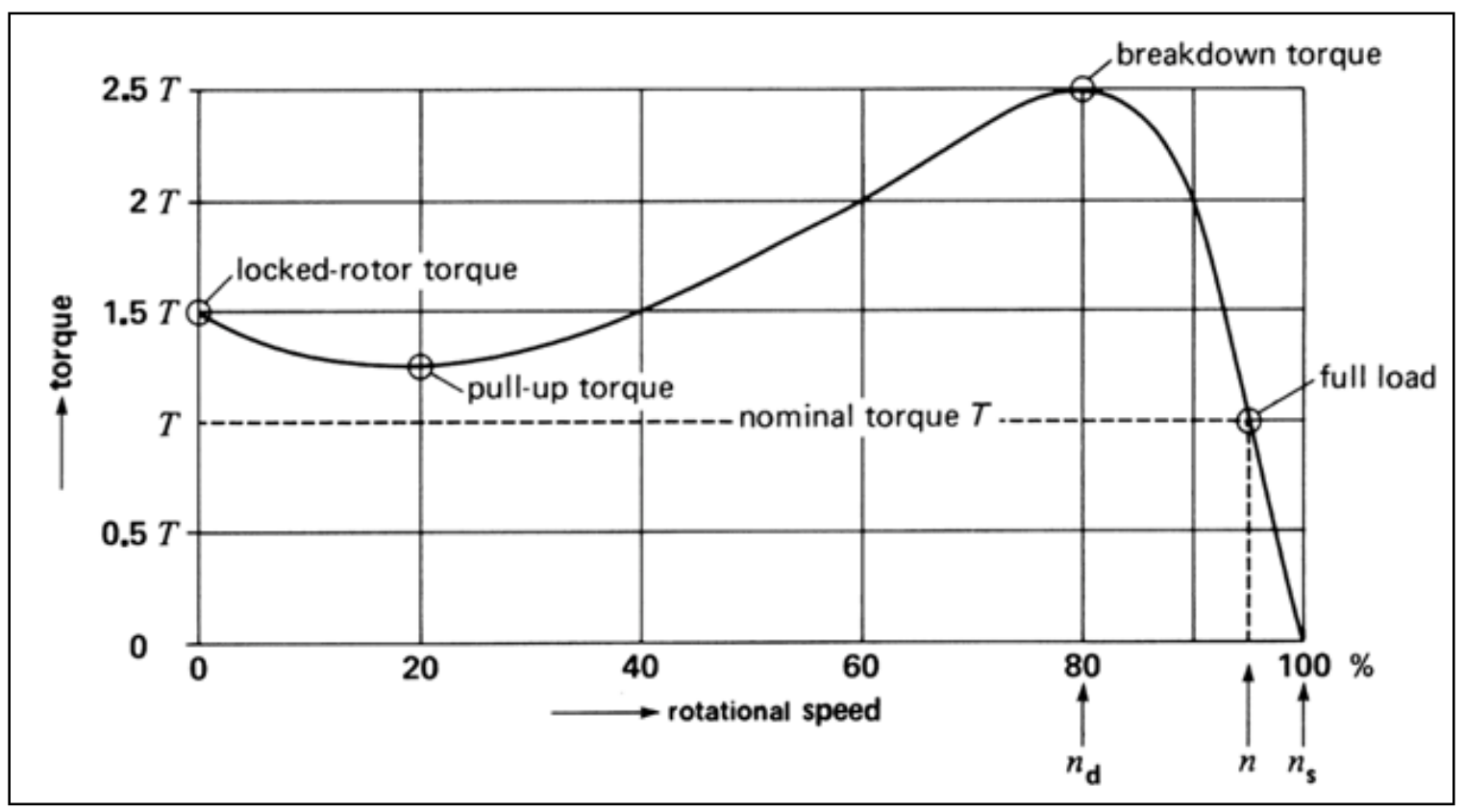

Figure 8- Typical torque-speed curve of a 3-phase squirrel-cage induction motor

The induction motor's rotor is always trying to align itself with the rotating stator field, which means, the rotor speed is always less than synchronous speed. On the other hand the synchronous motor's rotor will lock into the rotating field, hence it rotates at synchronous speed. The stator of Synchronous motors are manufactured similar to the stator of induction motors, and are energized with three-phase AC currents. Most synchronous rotors have salient poles that have coils of wire wound around them with the coils connected to a rotor shaft through slip rings.

Usually, synchronous motor rotors have Squirrel Cage type bars placed on the top of the pole faces. A synchronous motor cannot start by itself. Therefore, squirrel cage bars will enable the rotor to act like an induction motor, so it will start rotating. Once the motor speed is close to the Synchronous Speed, the rotor will be energized with DC current and the salient poles will be magnetized. Then, the salient rotor will lock into the rotating stator field. Note that at synchronous speed, no current is induced in the bars since $\mathrm{fr}=\mathrm{S}^{*} \mathrm{f}$, and slip $\mathrm{S}$ is equal to zero. Smaller synchronous motors have permanent magnet rotors. Pull in torque is the amount of torque necessary to align the rotor and stator fields when the motor starts. Pull out torque is the amount of load that is required to take the rotor field out of alignment with the stator field. Increasing the DC rotor excitation current increases the pull out torque value. 
Alternative Current (AC) Synchronous Motors (SM) are among the most efficient electric motors. One unique quality of a synchronous motor is the ability to operate with a leading power factor characteristic. Synchronous motors supplied with larger than required DC rotor-current excitation, operate with a leading power factor (See Figure 9). This feature called "over excitation", may be used for power factor correction. Due to the number of motors and transformers in industrial plants, the power factor is usually lagging. Therefore, using a leading power factor can bring the overall power factor close to one. Under normal operating conditions when SM is not used for power factor correction, synchronous motors run at a constant synchronous speed.

Two laboratory experiments are assigned in order to complement classroom teaching. A brief description of these experiments is listed below. Students are required to use MatLab for determining the pre and post laboratory parameters. In experiment \#6, open and short circuit tests are performed to calculate the equivalent circuits of Hampden's three-phase squirrel cage induction motors. Then, three-phase squirrel cage induction motors on Hampden stations are operated under load, and data is collected to plot the Speed-Load characteristic curves. In experiment \#7, synchronous motors on Hampden stations are tested and data is collected to plot their speed-torque characteristic curves. Rotor currents are also varied for the synchronous motors to demonstrate the concept of operating under lagging, unity, and leading power factors.

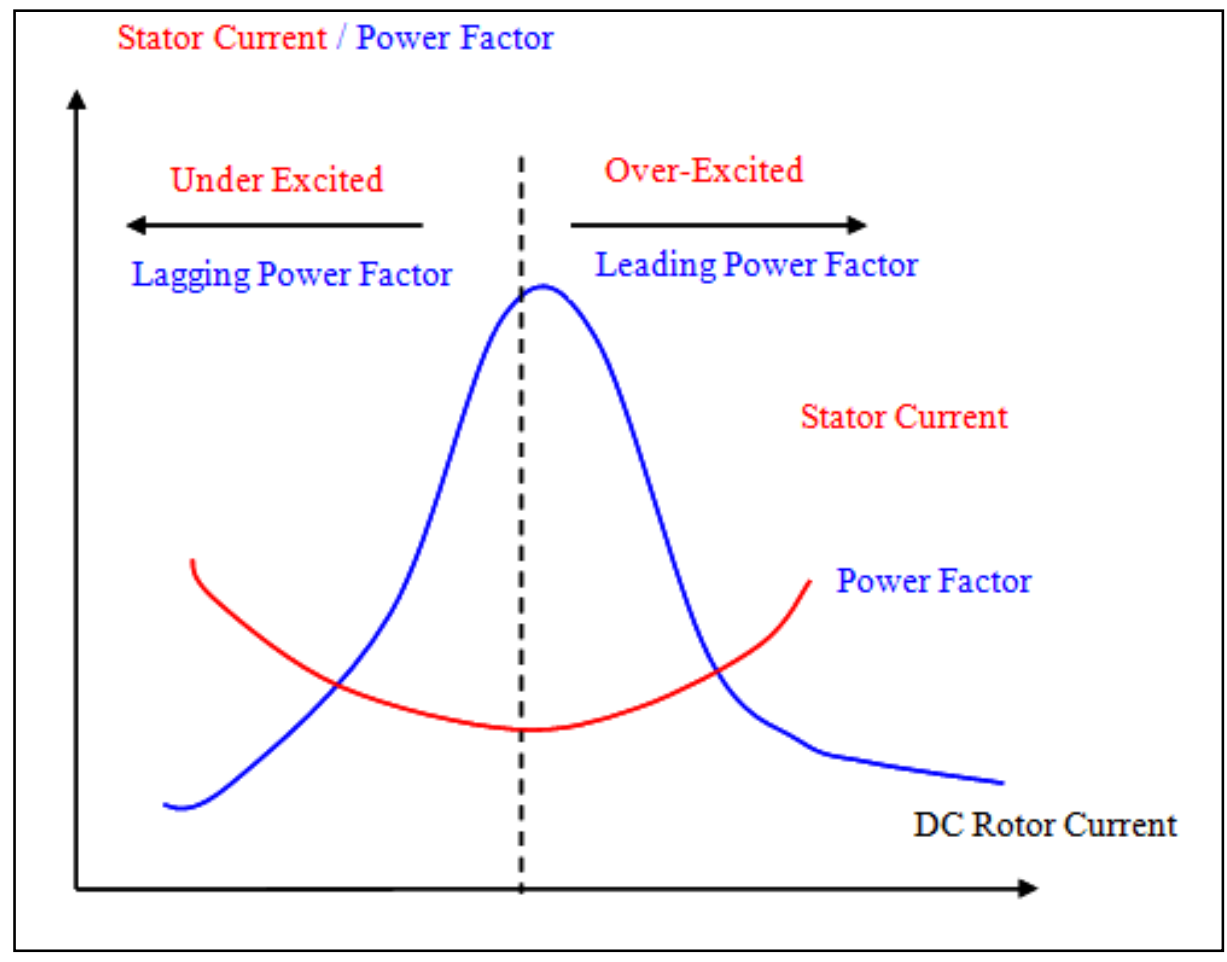

Figure 9- Synchronous Motor Characteristics 


\section{Conclusion:}

A three-credit hour, one-quarter long course entitled "Rotating Electric Machines" is taught in the School of Electronic and Computing Systems (SECS) at the College of Engineering and Applied Science (CEAS). This course is offered twice during winter and spring quarters. A onecredit hour, laboratory course is also required to be taken during the quarter in which students are enrolled in the "Rotating Electric Machines" class. MatLab was required for analyzing devices and plotting characteristics data. Using MatLab enabled the class to cover more topics during the ten weeks quarter term period. Students' comments were generally positive. Some of those comments listed below are exactly as students wrote it in their course evaluation form.

$>$ I think the amount of material was adequate for the depth that we reach in this class.

I think it would be useful to have a class about controls of the different motors and their applications.

$>$ In this class I feel we covered an adequate amount of material. It was well paced \& covered many good topics. I feel that less review in the beginning of the class would have been better so that we could cover more material. I would have liked to learn more about transformers.

$>$ The material covered was the most possible within 10 weeks. As many types of AC/DC motors as possible were covered with some details included. Maybe make this a 5 credit hour course. One hour per day meeting that would allow more detail in all of the previously covered topics. Great work.

I can suggest using flash presentations to better illustrate the principle of operation of the electric machines. Other than that, the coverage is rather good.

I think you should breakdown a transformer equivalent circuit and explain with much detail.

$\mathrm{AC}$ motor was a little too much.

Sometimes material seemed to be covered too quickly. I liked the examples on BlackBoard site. Cover more examples similar to what the exam format would be.

This course I feel covered enough information that is pertinent to electric machines. A power electronics class would be a nice addition to possibly complimenting rotating machines.

I enjoyed this class a lot. I learned a lot about AC and DC machines. I would have liked to learn more about stepper and even servo motors. At the beginning there was a lot of homework and quizzes but it was needed. Max is my favorite teacher and I like his teaching. 
Overall I thought the material covered was both practical and important. There was maybe too much covered although it would have been nice to cover stepper motors, maybe make course into 2 quarters.

This paper explained how to teach important theories and applications of electric machines with the help of MatLab software, during one quarter term. The author intended to demonstrate that using software such as MatLab as a tool can make it possible to teach important electromechanical topics in electrical engineering curriculums, during a limited time, in one quarter or one semester.

\section{Bibliography:}

1. Theodore Wildi, Electrical Machines, Drives, and Power Systems, 6th edition, Prentice-Hall, 2006.

2. Hubert, Electric Machines, 2nd Edition, Prentice-Hall, 2002.

3. "Teaching an Undergraduate Electromechanical Course", 2010 IEEE/NAECON Annual Conference Proceeding, Collaborative \& Cognitive Processing, Session I, Paper \#640, July 2010.

4. Fitzgerald, Kingsley and Umans, Electric Machinery, 6th edition, McGraw-Hill, 2005.

5. Chapman, Electric Machinery Fundamentals, $5^{\text {th }}$ edition, McGraw-Hill, 2011. 